\title{
Use of a Common Garden Experiment in Selecting Adapted Beech Provenances for Artificial Stand Restoration
}

\author{
Sanja Bogunović ${ }^{1 *}$, Saša Bogdan ${ }^{2 *}$, Miran Lanšćak ${ }^{1}$, Nevenka Ćelepirović ${ }^{1}$, Mladen Ivanković ${ }^{1}$
}

(1) Croatian Forest Research Institute, Division for Genetics, Forest Tree Breeding and Seed Husbandry, Cvjetno naselje 41, HR-10450 Jastrebarsko, Croatia; (2) University of Zagreb, Faculty of Forestry, Department of Forest Genetics, Dendrology and Botany, Svetošimunska 25, HR-10000 Zagreb, Croatia

* Correspondence: e-mails: sanjam@sumins.hr; sbogdan@sumfak.unizg.hr

\begin{abstract}
Citation: Bogunović S, Bogdan S, Lanšćak M, Ćelepirović N, Ivanković M, 2020. Use of a Common Garden Experiment in Selecting Adapted Beech Provenances for Artificial Stand Restoration. Southeast Eur for 11(1): 1-10. https://doi. org/10.15177/seefor.20-07.

Received: 27 Feb 2020; Revised: $20 \mathrm{Apr}$ 2020; Accepted: 21 Apr 2020; Published online: 30 Apr 2020
\end{abstract}

\begin{abstract}
Increased frequency of extreme weather events has seriously affected forestry operations in south-eastern Europe. A precondition for effective artificial restoration of disturbed forest stands is site-adapted forest reproductive material (FRM). Common garden experiments (provenance trials) may assist in selecting such FRM. The main objective of this study was to establish among-provenance variation pattern using data from a beech provenance trial. Usefulness of the results in selecting seed sources for restoration of European beech stands is discussed. The trial was set up in 2007, at a slope of Medvednica mount facing north-west at 730-750 m above sea level. Plant heights were measured and survival scored in 2008 and 2015. Height increments were calculated and processed to determine variance components due to various effects. Highly significant provenance-by-block interaction was revealed, indicating strong microsite effects on provenance performances. Therefore, corrections were made and provenance mean height increments recalculated. Provenance mean height increment multiplied with survival was used as a measure of a provenance's adaptedness. Regression tree (RT) analysis was used to determine the pattern of among-provenance variations. A set of provenance clusters was grown using climatic variables related to the provenance stands of origin as criteria. All analyzed effects were significant (provenance: $F=2.07, p<0.05$; block: $F=5.07, p<0.05$; provenance by block interaction: $F=7.32, p<0.001$ ). Data corrections reduced the interaction effect, thereby increasing reliability of calculated provenance adaptedness indices (Al). Provenances were grouped into 4 clusters due to elevation, mean July temperature and summer heat-to-moisture index (SHM). Cluster 4 , containing provenances from the highest altitudes $(>750 \mathrm{~m})$, had the highest mean $\mathrm{Al}(143.9 \pm 8.4 \mathrm{~cm})$. The lowest mean $\mathrm{Al}$ $(106.7 \pm 14.8 \mathrm{~cm})$ had cluster 1 , containing provenances from lower altitudes with lower mean July temperatures $\left(\leq 18.4^{\circ} \mathrm{C}\right)$. Provenances originating from lower elevations with higher mean July temperatures $\left(>18.4^{\circ} \mathrm{C}\right)$ were further divided into two clusters due to the SHM variable. Cluster 2 had the second highest mean Al $(141.2 \pm 1.5 \mathrm{~cm})$ and contained provenances from relatively wetter habitats (SHM $\leq 48.2$ ). Cluster 3, containing provenances from relatively arid habitats $(\mathrm{SHM}>48.2)$, had significantly lower mean Al $(116.8 \pm 8.6 \mathrm{~cm})$. Established among-provenance variation pattern might be used as a tool in selecting seed sources for artificial restoration of beech stands at mount Medvednica. It is advisable to use FRM from higher altitudes and/or from slightly lower altitudes (up to $150 \mathrm{~m}$ lower than a restoring site) but featured with warmer and drier conditions compared to the trial. Generally, provenance trials should be utilized as a valuable decision tool in restoring disturbed forest stands but may also be misleading if not well designed and analyzed.
\end{abstract}

Keywords: provenance trial; microsite variation; adaptedness; ecotype variation; natural selection; regression tree analysis 


\section{INTRODUCTION}

Frequency of extreme weather events has recently increased at wide-European scale affecting forest ecosystem functioning and services provisioning to society (Neumann et al. 2017). Artificial restoration of forest stands disturbed by such events has become important issue, especially in southeast Europe where natural forest stand regeneration has been traditionally practiced. Nevertheless, artificial restoration (by planting saplings) of disturbed forest stands is often the only option. Long-term restoration success depends on appropriate seed source (provenance) selection (Ivetić and Devetaković 2016). The availability of quality forest reproductive material (FRM) is a prerequisite for efficient and successful artificial stand restoration. Quality FRM means, among other things, seeds or seedlings that are well adapted to habitat conditions prevailing in stands to be restored. Theoretically, an adapted FRM is one that originates from one or more provenances of a target species that are adapted to specific environmental conditions because their genetic constitution has been shaped by natural selection (Epperson 1992, Savolainen and Pyhäjärvi 2007). Therefore, obtaining FRM from provenances thriving in the same environmental conditions as a local provenance (the one we want to artificially restore) seems like a simple and quick solution. However, identifying such provenances is by no means an easy task. On the one hand, it is difficult to recognize the complexity of environmental conditions (their changes and interactions) that prevail in a specific provenance area. On the other hand, there is no perfect adaptation because various factors affect genetic constitution of a provenance (not only natural selection), thus reducing the adaptedness of FRM (Kremer et al. 2012). Common garden experiments (provenance trials), where progenies from different provenances are tested under similar environmental conditions, are a useful tool for selecting FRM adapted to a habitat (Mátyás 1996). Ranking progenies due to its performance in provenance trials has been frequently used as a mean of determining seed zonation and seed source selection (Westfall 1992, Rehfeldt et al. 1999, Kleinschmit et al. 2004, Hamann et al. 2011).

However, the usefulness of a provenance trial largely depends on the representativeness of sampled progenies as well as on the effects of environmental variation within a trial site on the assessment of among-provenance variation. If progenies included in a trial are not a representative sample of within-species variation (both at provenances and a species level), then the trial results are of reduced utility. In addition, homogenization of environmental variations in a trial is the basis for reliable genetic evaluation of provenances. The significant influence of micro-site variations on genetic evaluation has been a common problem of forest tree provenance trials (Magnussen 1993, Dutkowski et al. 2002, 2006, Funda et al. 2007, Gömöry et al. 2011). The problem can be addressed prior to establishment of experimental plantations, by considering and using alternative planting designs (Libby and Cockerham 1980, Coterill and James 1984). However, most forest trials have been traditionally set up according to randomized complete block design with large contiguous plots and at relatively large areas with pronounced micro-site heterogeneities. It is very difficult to reset such a trial by subsequent blocking in order to reduce micro-site variations (Gömöry et al. 2011). Despite mentioned problems, common garden trials are still the best available source of information on provenance adaptedness to specific habitat conditions.

Like in most parts of the region, forests in the Republic of Croatia are generally managed based on close-tonature paradigm, i.e. forest stands are preferably naturally regenerated (Matić 1999, Anić 2007). However, increased incidence of extreme weather events during last decade (e.g. windstorms) has significantly increased a need for artificial restoration of forest stands (Vuletić et al. 2014). Among many examples, the mount Medvednica was hit by two strong and several weaker windstorms damaging many trees, mostly of European beech (Balija 2015, HINA 2019). Therefore, artificial restoration of devastated beech stands at mount Medvednica has become the only option. Therefore, new approaches should be considered for long-term restoration success including selection of site-adapted provenances.

With this study, we tried to rank tested beech provenances with respect to their adaptedness to specific habitat conditions at the Medvednica provenance trial. The aim was to establish a pattern of among-provenance variation, which may be used as a decision tool in selecting adapted forest reproductive material for artificial restoration of disturbed beech stands. To our knowledge, this is the first attempt to make such use of a provenance trial in this part of Europe.

\section{MATERIALS AND METHODS}

\section{Field Trial}

Beech provenance trial Medvednica is located at the homonymous mountain near Zagreb, the capital of Croatia (N $45^{\circ} 53^{\prime} 5.6^{\prime \prime}$; E $15^{\circ} 55^{\prime} 13.8^{\prime \prime}$ - Figure 1).

The trial was established in spring 2007 with progeny from 21 provenances originating from 9 European countries (Figure 1, Table 1). One provenance was omitted from this study due to its high mortality. The saplings were grown and provided by the Thünen-Institute for Forest Genetics in Grosshansdorf, Germany. The trial was a part of the 2007 international series of beech provenance trials (Von Wuehlisch et al., 2010). Taxonomically, 19 provenances belong to European beech (Fagus sylvatica L.) and one provenance belongs to Oriental beech (Fagus orientalis Lipsky - provenance TR62, Table 1). The trial was set up according to a randomized complete block (RCB) experimental design with three replications (blocks), at a slope facing north-west approx. $740 \mathrm{~m}$ above sea level (729 - $750 \mathrm{~m}$ ). Blocks were oriented perpendicular to the slope exposure. Each provenance was represented by 50 plants per block, planted in rectangular plots with $2.0 \times 1.0 \mathrm{~m}$ spacing. The plants representing various provenances were not of the same age. Ten provenances were 2 years old, eight were 3 years old and two provenances were 4 years old in the spring of 2007 (Table 1).

\section{Data Collection and Statistical Analyses}

Heights of all plants were measured (with $1 \mathrm{~cm}$ precision) while plant survival was visually determined and scored in 2008 and 2015, after the $1^{\text {st }}$ and the $8^{\text {th }}$ growing seasons at the trial site. Height increments between 2008 and 2015 (HI_08_15) 


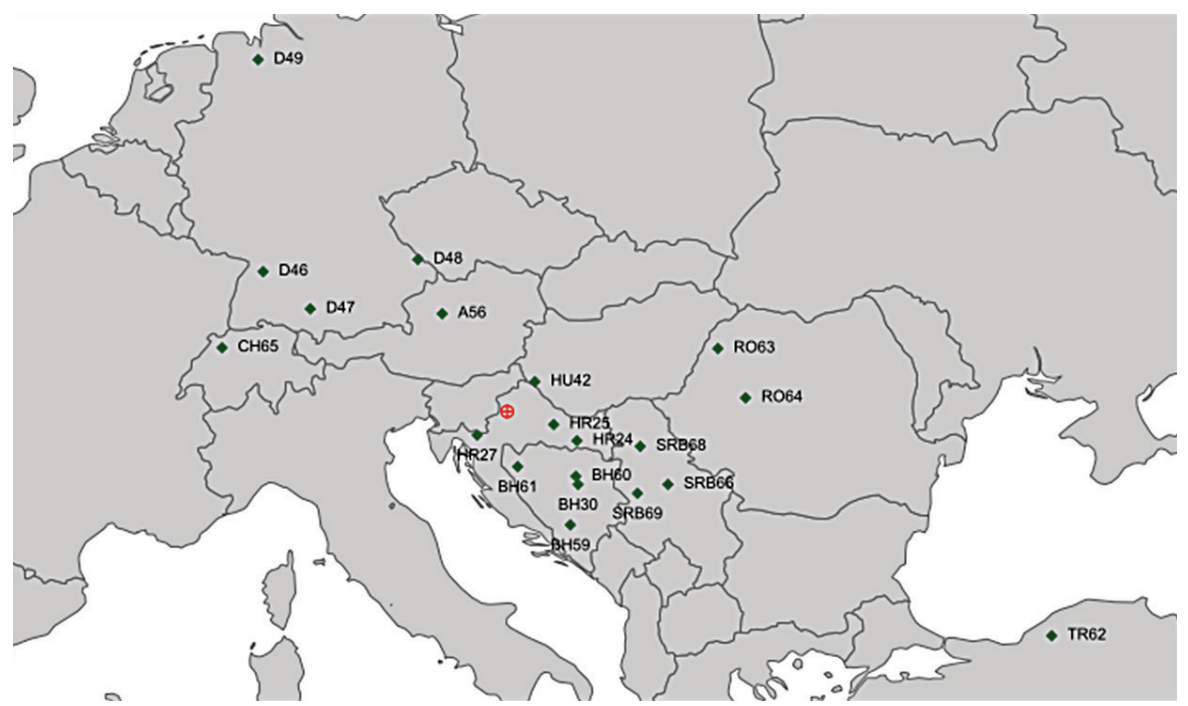

Figure 1. Geographic position of beech provenance stands of origin and provenance trial Medvednica (red label).

Table 1. Studied beech provenances and climate data of their stands of origin for the period 1981-2009. Climate data has been generated with the ClimateEU v4.63 software, available at http://tinyurl.com/ClimateEU.

\begin{tabular}{|c|c|c|c|c|c|c|c|c|c|c|}
\hline $\begin{array}{l}\text { Provenance } \\
\text { label }\end{array}$ & $\begin{array}{c}\text { Provenance } \\
\text { name }\end{array}$ & $\begin{array}{c}\text { Seed } \\
\text { sampled }\end{array}$ & $\begin{array}{l}\text { Country } \\
\text { abbrev. }\end{array}$ & $\begin{array}{l}\text { MAT } \\
\left({ }^{\circ} \mathrm{C}\right)\end{array}$ & $\begin{array}{l}\text { Elev } \\
(\mathrm{m})\end{array}$ & $\begin{array}{c}\text { MWMT } \\
\left({ }^{\circ} \mathrm{C}\right)\end{array}$ & $\begin{array}{l}\text { TD } \\
\left({ }^{\circ} \mathrm{C}\right)\end{array}$ & $\begin{array}{l}\text { MAP } \\
(\mathrm{mm})\end{array}$ & $\begin{array}{l}\text { MSP } \\
(\mathrm{mm})\end{array}$ & SHM \\
\hline A56 & Scharnstein,Mitterndorf & 2003 & A & 8.5 & 480 & 18.4 & 20.2 & 1323 & 709 & 26.0 \\
\hline $\mathrm{BiH} 30$ & Tajan, Zepce & 2003 & $\mathrm{BH}$ & 9.2 & 700 & 19.2 & 20.6 & 891 & 398 & 48.2 \\
\hline BH59 & Vranica-Bistrica & 2004 & $\mathrm{BH}$ & 10.0 & 750 & 19.5 & 18.6 & 1089 & 402 & 48.5 \\
\hline $\mathrm{BH} 60$ & Crni vrh & 2004 & $\mathrm{BH}$ & 10.1 & 500 & 20.1 & 20.7 & 882 & 396 & 50.7 \\
\hline BH61 & Grmec,Bastra-Corkova & 2004 & $\mathrm{BH}$ & 8.6 & 720 & 18.4 & 19.7 & 1102 & 433 & 42.5 \\
\hline $\mathrm{CH} 65$ & Sihlwald, 101 & 2004 & $\mathrm{CH}$ & 6.6 & 1050 & 15.4 & 17.3 & 1559 & 651 & 23.7 \\
\hline D46 & Pfalzgrafenweiler,XII Abt37 & 2003 & D-BW & 8.2 & 700 & 17.4 & 18.2 & 1076 & 458 & 38.0 \\
\hline D47 & Schelklingen, IX 23-25 81023 & 2002 & D-BW & 8.1 & 650 & 17.6 & 18.8 & 1053 & 554 & 31.8 \\
\hline D48 & Hoellerbach 81024 & 2003 & D-BY & 6.5 & 755 & 16.1 & 19.7 & 930 & 464 & 34.7 \\
\hline D49 & Hasbruch 81001 & 2002 & $\mathrm{D}-\mathrm{NI}$ & 9.2 & 35 & 17.3 & 15.7 & 767 & 354 & 48.8 \\
\hline HR24 & Sjeverni Dilj Caglinski & 2003 & $\mathrm{HR}$ & 10.1 & 350 & 20.2 & 20.8 & 811 & 391 & 51.7 \\
\hline HR25 & Vrani kamen $12 a, 15 b$ & 2003 & $\mathrm{HR}$ & 9.0 & 600 & 19.0 & 20.4 & 973 & 450 & 42.2 \\
\hline HR27 & Vrbovsko-Meletka 36b & 2003 & $\mathrm{HR}$ & 8.7 & 800 & 18.4 & 19.1 & 1689 & 652 & 28.2 \\
\hline $\mathrm{HU} 42$ & Valkonya 19A & 2003 & $\mathrm{HU}$ & 10.1 & 300 & 20.4 & 21.3 & 775 & 412 & 49.5 \\
\hline RO63 & Alesd, U.P.II / 51A & 2004 & RO & 8.7 & 490 & 18.9 & 21.7 & 607 & 309 & 61.1 \\
\hline RO64 & Alba-Iulia, U.P.V/154A & 2004 & RO & 7.4 & 860 & 17.1 & 19.9 & 707 & 404 & 42.3 \\
\hline SRB66 & Avala & 2004 & SRB & 10.1 & 475 & 19.8 & 20.6 & 677 & 320 & 61.9 \\
\hline SRB68 & Fruska gora & 2004 & SRB & 10.4 & 370 & 20.7 & 21.4 & 666 & 319 & 64.9 \\
\hline SRB69 & Cer & 2004 & SRB & 8.9 & 745 & 18.4 & 20.0 & 811 & 379 & 48.5 \\
\hline TR62 & Devrek Tefen BA 3 & 2004 & TR & 10.0 & 950 & 19.3 & 18.6 & 779 & 256 & 75.5 \\
\hline Trial site & Medvednica & & & 7.2 & 730 & 17.1 & 20.9 & 1205 & 575 & 29.8 \\
\hline
\end{tabular}

Country abbreviations: A - Austria; BH - Bosnia and Herzegovina; CH - Switzerland; D - Germany; HR - Croatia; HU - Hungary; RO - Romania; SRB - Serbia; TR - Turkey.

Climate data: MAT - mean annual temperature; Elev - elevation; MWMT - mean warmest month (July) temperature; TD - continentality index; MAP - mean annual precipitation; MSP - mean summer (June-August) precipitation; SHM - summer heat to moisture index (MWMT/ (MSP/1000)); Methodology of the climate data calculations described in Wang et al. (2011). 
were calculated as difference between plant heights in 2015 and 2008. Correlation between initial plant heights and their HI_08_15 was calculated using Hmisc package in R (Frank E Harrell Jr, with contributions from Charles Dupont and many others. (2019). Hmisc: Harrell Miscellaneous. R package version 4.3-0. https://CRAN.R-project.org/package=Hmisc). The correlation was low $(R=0.23)$ and non-significant $(p<0.0001)$ and thus we assumed that HI_08_15 was not biased due to age differences among provenances. Therefore, data on individual height increments were used in further analyses.

Factorial analyses of variance (ANOVA) were performed on HI_08_15 data using the MIXED procedure (SAS/STAT software, a free version of SAS University Edition, by SAS Institute Inc., Cary, NC, USA) to determine the variance components due to effects of the blocks, provenances and provenance-by-block interactions according to the following linear model (Equation 1):

$$
\mathrm{y}_{\mathrm{ijk}}=\mu+\mathrm{B}_{\mathrm{i}}+\mathrm{P}_{\mathrm{j}}+\mathrm{BP}_{\mathrm{ij}}+\varepsilon_{\mathrm{ijk}}
$$

where: yijk - individual value of a trait; $\mu$ - overall mean; $\mathrm{Bi}$ random effect of the block $i, i=1,2,3 ; \mathrm{Pj}$ - random effect of the provenance $\mathrm{j}, \mathrm{j}=1,2, \ldots, 20 ; \mathrm{BPij}$ - random effect of the provenance-by-block interaction; $\varepsilon$ ijk - random error.

Since highly significant provenance-by-block interaction was revealed, Tukey-Kramer HSD test was used to determine statistical significance of differences among provenance-byblock least square means (LSmeans). Only two provenances (R063 and TR62) had no significant differences among block LSmeans. Most provenances had one significantly different block LSmean and two provenances had all three block LSmeans significantly different among themselves (HR24 and A56). Therefore, provenances HR24 and A56 were excluded from further analyses, and data from significantly different blocks within provenances were omitted from further analyses, as well. Therefore, overall provenance mean height increments were recalculated with remaining data using proc MEANS in SAS. Above mentioned data corrections were done to reduce provenance-by-block interactions i.e. to reduce microsite effects on provenance mean estimates.
Provenance mean height increment multiplied with survival was used as a measure of a provenance's adaptedness (i.e. adaptedness index - Al, Ishizuka and Goto 2012) to the trial site conditions. Regression tree (RT) analysis was used to determine the pattern of among-provenance variation for Al, using the Orange Tree Widget (Demšar et al. 2013). A set of clusters was grown by repeated binary splits of the provenances. Splits were made using environmental predictor variables as criteria, so that the homogeneity of genetic response variable (i.e., the provenance mean Al) is maximized. No assumptions were made about the mathematical nature of the relationship between response and predictor variables. Various climatic variables related to the provenance stands of origin were used as environmental predictor variables. To characterize the long-term climate conditions at the provenances stands of origin, we used interpolated climate data for the 1981-2009 reference period that was generated with the ClimateEU software (Hamann A, Wang T, Spittlehouse DL, Murdock TQ, 2013; ClimateEU, unpublished software package for Europe freely available at http://www. ualberta.ca/ ahamann/ data/climateeu.html). Estimation of biologically relevant climate variables, lapse-rate elevation adjustments, and data extraction from grids for the sample locations were carried out with the ClimateEU software, as well. A detailed explanation of the estimation of all available climate variables given by the ClimateEU software can be found in Wang et al. (2011). Significance of difference among the clusters given by RT analyses was calculated with Tukey HSD test.

\section{RESULTS}

Average height increment (HI_08_15) of all plants at the trial was $135.7 \pm 56.4 \mathrm{~cm}$ (prior to data corrections). However, variations in height increment among provenances were evident (Figure 2). Generally, the lowest average height increment was achieved by provenance D47 $(109.0 \mathrm{~cm})$ and the highest by provenance HR24 (176.9 cm). Large HI_08_15 variations within all provenances could have been observed (Figure 2).

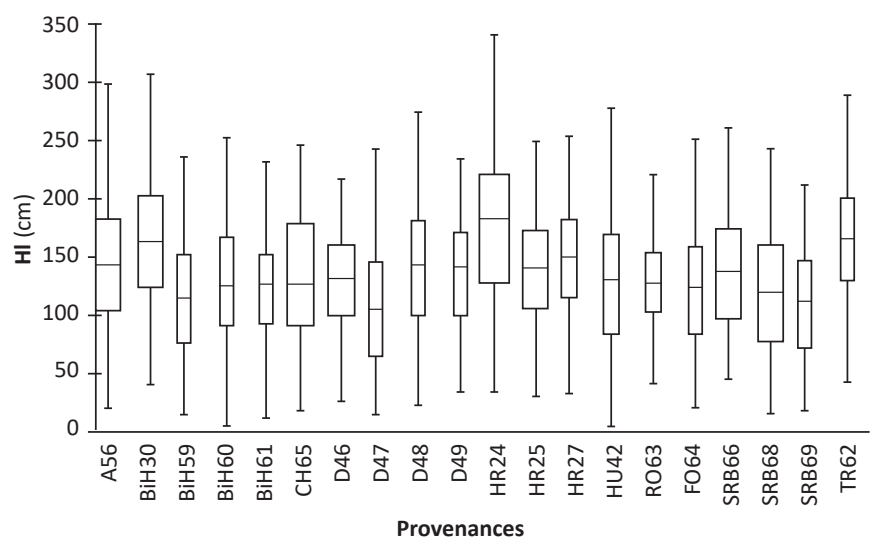

Figure 2. Boxplot of height increment (HI) data per provenance (HI between 2008 and 2015). 
The coefficient of variation (CV) ranged from $31.6 \%$ (RO63) to $52.2 \%$ (D47). The analysis of variance revealed that all examined effects were statistically significant (provenance effect: $F=2.07, p<0.05$; block effect: $F=5.07$, $p<0.05$; provenance by block interaction: $F=7.32, p<0.001)$. The highest proportion of total variance and the highest level of statistical significance had the provenances by block interaction effect. Generally, survival at the trial over the analyzed period (2008-2015) was rather high (95\%). Of course, variations in survival among provenances were observed (Figure 3).

Provenance D46 had the lowest survival (0.83), while provenance R064 exhibited the highest survival (1.0). However, significant differences in provenance survival were found regarding the blocks. For example, survival of provenance D46 was 0.73 in block 1 but 0.94 in block 2 . The product of average provenance height increment and survival (adaptedness index - Al) was an indicator of its productivity, i.e. adaptedness to specific habitat conditions (Ishizuka and Goto 2012). Provenance Als per block before data corrections are shown in Figure 4a. Significant provenance by block interactions is visualized by pronounced changes in provenance rankings across blocks. Four groups of provenances can be distinguished from Figure 4a: i) provenances that showed the highest mean $\mathrm{Al}$ in the first block, while their mean $\mathrm{Al}$ decreased towards the $2^{\text {nd }}$ and $3^{\text {rd }}$ blocks (those are indicated by the solid red lines in Figure $4 a)$; ii) provenances that had similar (lower) mean Al values at blocks 1 and 3, while highest mean $\mathrm{Al}$ at block 2 (those are indicated by dotted black lines - Figure 4a); iii) provenances that had similar (higher) mean $\mathrm{Al}$ values at blocks 1 and 3 while lowest mean $\mathrm{Al}$ at block 2 (those are indicated by dashed blue lines - Figure 4a); iv) stable provenances whose mean Al values were similar at all three blocks (indicated by the solid black lines - Figure 4a). Provenance BH61 stands out specific to all others because its mean Al value was lowest at blocks 1 and increased towards blocks 2 and 3 (indicated by a solid gray line - Figure 4a). We tried to reduce the effect of provenance by block interaction by excluding data from the blocks whose LSmeans (of HI08_15) were significantly different from the others. Two provenances were completely excluded from further analyses (A56 and HR24) because their LSmeans differed significantly among all three blocks. By this procedure, we significantly reduced the variation of a provenance $\mathrm{Al}$ at the trial (i.e. microsite effects on calculations of overall provenance mean Al were reduced) (Figure 4b).

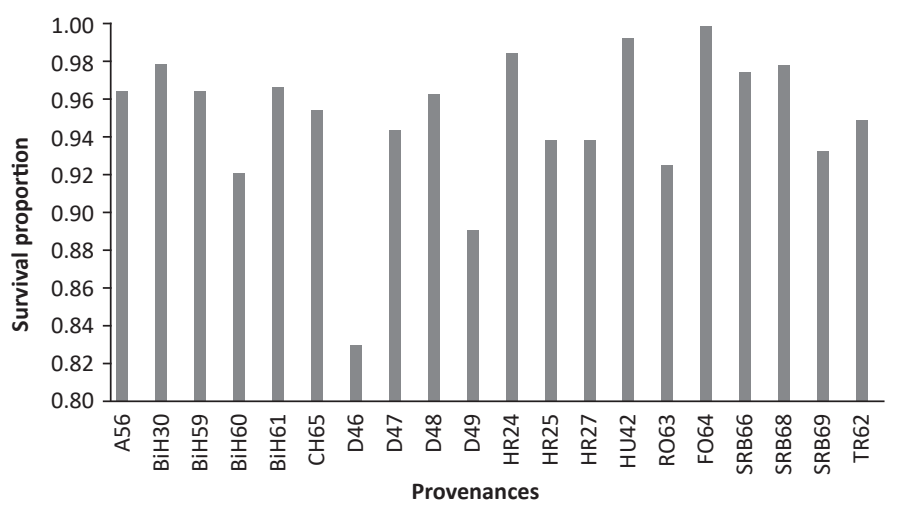

Figure 3. Proportion of living plants per provenance (survival between 2008 and 2015).
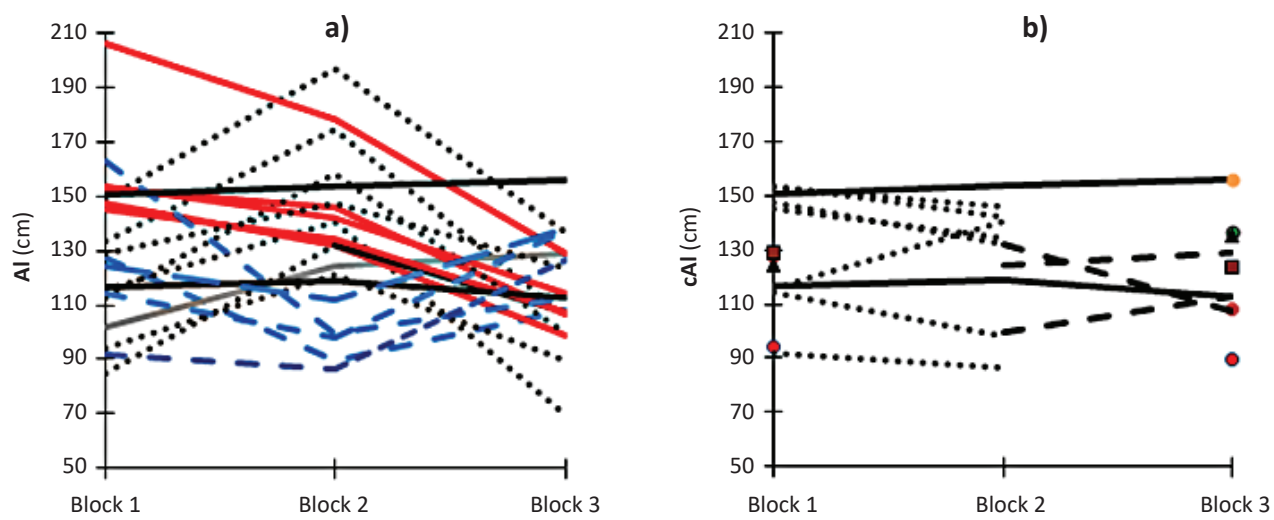

Figure 4. Provenance adaptedness index - Al (mean height increment $\times$ survival) per block. a) showing large provenance by block interaction before data corrections. b) Corrected provenance adaptedness index (cAl), after exclusion of data from blocks which HI_08_15 LSmean showed a significant difference from other blocks within the same provenance (showing reduction in provenance by block interaction). 
Regression tree (RT) analysis was performed to determine the pattern of among-provenance variation regarding corrected adaptedness index (cAl). The RT analysis initially separated the provenances due to elevation - Elev (Figure 5).

Cluster 4 (Figure 5, 6) had the highest mean cAl $(143.9 \pm 8.4$ $\mathrm{cm}$ ). It contained provenances (D48, HR27, CH65, RO64 and TR62) originating from highest altitude habitats (Elev $>750$ $\mathrm{m}$ ). Other provenances (originating from lower altitude habitats) were divided by the variable July mean temperature (MWMT). The lowest mean cAl $(106.7 \pm 14.8 \mathrm{~cm})$ exhibited cluster 1 (Figure 5,6 ). It contained provenances originating from habitats characterized by relatively lower average July temperatures (MWMT $\leq 18.4^{\circ} \mathrm{C}$ ). These were provenances $\mathrm{D} 46$, D47, D49, SRB69 and BH61. On the other hand, provenances originating from habitats characterized by relatively higher mean July temperatures (MWMT $>18.4^{\circ} \mathrm{C}$ ) were divided into two clusters due to the SHM variable (summer heat-tomoisture index). Cluster 2 (Figure 5, 6) contained provenances originating from habitats with relatively lower SHM values (SHM $\leq 48.2)$. This cluster had the second highest mean cAl $(141.2 \pm 1.5 \mathrm{~cm})$. Cluster 2 contained provenances BH30 and HR25. Cluster 3 (Figure 5,6) had a significantly lower mean cAl $(116.8 \pm 8.6 \mathrm{~cm})$, and contained provenances (BH59, BH60, HU42, RO63, SRB66, and SRB68) originating from habitats that were characterized with relatively higher SHM (>48.2). The Tukey HSD test separated clusters into two groups that were significantly different between each other. Cluster 1 and Cluster 3 were in the first group, while Cluster 2 and Cluster 4 were in the second group (Figure 5). The results of the RT analysis indicated that among-provenance variation due to progeny mean CAl at the Medvednica trial can be primarily explained by differences in altitude among the provenance stands of origin. Provenances originating from higher (>750 m) altitudes showed, on average, the highest level of adaptedness to environmental conditions of the trial. Among the provenances originating from relatively lower altitudes $(<750 \mathrm{~m})$, the main discriminating climatic variables explaining the amongprovenance variation were those associated with summer heat (MWMT) and with combination of heat and humidity of a habitat (SHM), also during summers. Relatively higher levels of adaptedness of the provenances originating below $750 \mathrm{~m}$ a.I.s. were those originating from habitats characterized with relatively higher mean July temperatures, but at the same time from habitats with relatively higher rainfall in the summer. It is interesting to note that the site of the Medvednica trial is at an average altitude of $740 \mathrm{~m}$, its MWMT is $17.1^{\circ} \mathrm{C}$, and the SHM is 29.8 (Table 1). Thus, the results showed that provenances originating from higher altitudes as well as provenances originating from slightly lower altitudes, but in this case from habitats that are on average characterized with warmer and drier summers compared to the trial site (Cluster 4 - Figure 6), performed better adaptedness.

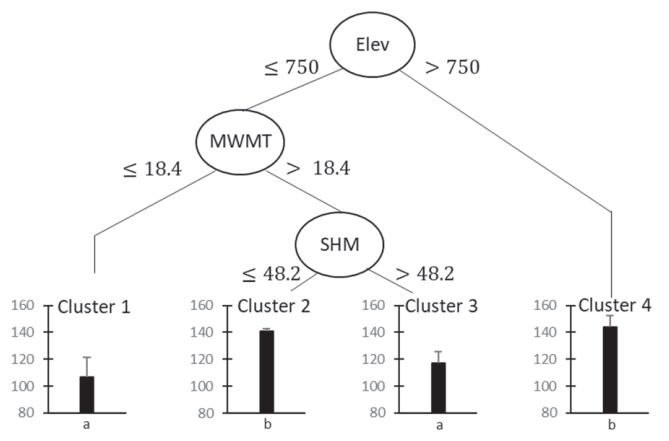

Figure 5. Regression tree analysis output showing clusters of provenances discriminated according to climate variables of their stands of origin. Elev - elevation; MWMT - mean warmest month temperature (July); SHM - summer heat to moisture index. Column charts represent mean (+standard deviation) of a cluster mean adaptedness index (cAl). Clusters labeled with the same letter were not statistically different.

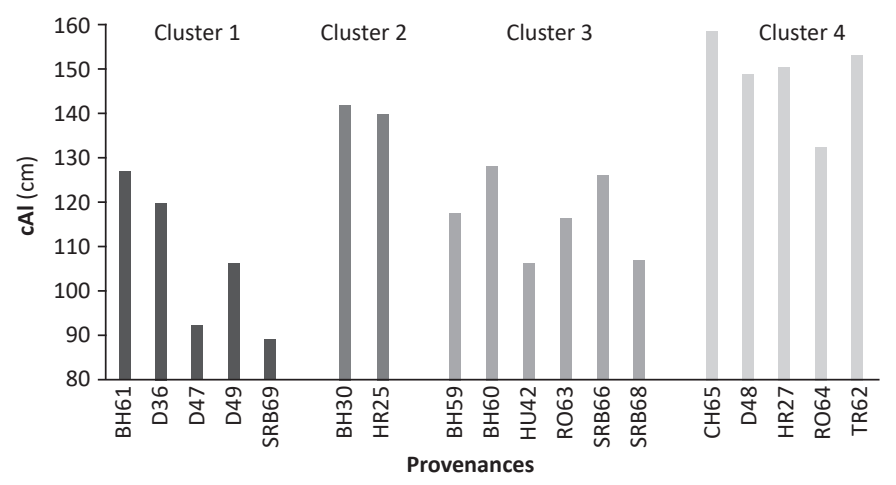

Figure 6. Corrected mean adaptedness index (cAl) of studied provenances at the trial Medvednica. Provenances grouped into four clusters due to regression tree analyses. 


\section{DISCUSSION}

Extreme weather events have increased in frequency affecting forest ecosystem functioning and services at wide European scale. Croatia has also experienced an increase in extreme weather events during this decade that caused significant disturbances of forest stands (Vuletić et al. 2014). For example, two strong and several milder windstorms hit Medvednica mount damaging many trees, mostly of European beech (Balija 2015, HINA 2019). Therefore, it is important to select habitat-adapted forest reproductive material (FRM) for efficient long-term restoration of damaged stands, in which results of provenance trials may significantly assist (Mátyás 1996).

We used index (Al) calculated as the product of average height increment and survival as a measure of a provenance adaptedness. However, highly significant effect of provenance by block interaction on height increment was revealed. This indicates strong effects of micro-site variations on provenance performance at the trial, which is why environmental impact on among-provenance variation cannot be ruled out. Highly significant provenance-by-block interaction significantly reduces reliability of genetic values estimation, that is, reliability of a common garden experiment serving as a tool for selecting adapted FRM. The effect of micro-site variations on growth and adaptive traits in forest tree provenance trials is a common problem (Hamann et al. 2002, Zas 2006, Gömöry et al. 2011). Indeed, this is a problem because the basic principle of genetic testing (i.e. common garden experiment) is to homogenize environmental influence and thus to determine genetic differences among tested genetic entries (e.g. provenances). The problem of "masking" genetic differences because of micro-site variations can be mitigated by careful trial design, for example by using non-contiguous plots and by reducing a block surface (Libby and Cockerham 1980, Coterill and James 1984). However, it is almost impossible to predict all diversity and interactivity of a site variations and to design a perfect trial at which environmental conditions will be ultimately homogeneous (Gömöry et al. 2011). Despite these problems, common garden trials are still the best available source of information on provenance adaptedness to specific habitat conditions. Given the significant differences in rankings of provenance adaptedness indices across blocks (Figure 4a), we tried to reduce provenance-by-block interaction effect on Al calculation by excluding data from blocks that significantly differed from other blocks, per each provenance.

With this approach, we were able to reduce the effect of micro-site variations on provenance mean Al assessments (Figure 4b). Being aware that the effect of micro-site variations can be reduced by other statistical methods (see Zas 2006 and references therein), we used this simpler but effective approach, in this case.

Tested provenances performed different adaptedness to the habitat conditions at the trial, regarding height increment and survival during the analyzed period (Figure $2,3)$. Differences in adaptedness may be explained, at least in part, by genetic differences among provenances, since the provenance effect for height increment was statistically significant. Genetic differentiation of common beech provenances for adaptive traits (drought resistance, frost tolerance, budburst, growth, survival) has been established through relatively many studies, both at wide-European (von Wuehlisch et al. 1995, Chmura and Rozkowski 2002, Ivankovic et al. 2011, Robson et al. 2012) and at regional levels (Müller and Finkeldey 2016, Pluess et al. 2016).

A regression tree analysis was used to determine the pattern of among-provenance variation. The provenances were separated into homogeneous clusters due to the corrected adaptedness index (cAl), based on various climate variables of their original habitats. Generally, all discriminatory climate variables were related to heat (MWMT) and to the combination of heat and humidity (Elev, SHM) of the provenance habitats of origin (Figure 5), while the correlation with their geographical location was not established. These results suggest an ecotypic pattern of among-provenance genetic variation that was shaped by natural selection in native habitats (at least partially), that is, the genetic structure of analyzed beech populations can be related to variations in their habitat's heat and humidity (Figure 5). The results corroborate other authors who reported an ecotypic pattern of among-provenance variation in common beech that was related to environmental variables of their native habitats (e.g., Ivanković et al. 2011, Dounavi et al. 2016, Horváth and Mátyás 2016, Pluess et al. 2016). Although ecotypic pattern of variation partly related to geographical location of provenances has also been reported by several authors (e.g. Chmura and Rozkowski 2002). Different conclusions about the spatial pattern of the European beech genetic structure indicate the need for further research on this topic.

The results of the study showed significantly better adaptedness of provenances originating from higher altitudes compared to the trial site, as well as of provenances from slightly lower (up to $\min .600 \mathrm{~m}$ a.s.l.) altitudes, but warmer and drier during the summer season than the trial site (Figure 5,6 , Table 1). It is interesting to emphasize that provenances from higher altitudes mostly originated from warmer and drier habitats relative to the trial site, apart from the $\mathrm{CH} 65$ provenance. Given that there has been a trend of increasing air temperatures and decreasing rainfall throughout Croatia since 1990, especially during the growing season (DHMZ 2013), it is not so surprising that provenances originating from warmer and drier habitats have shown better adaptedness to the trial site. It should be emphasized that the trial was set up on a cleared site of northwestern exposure. Therefore, experimental plants were likely exposed to large fluctuations in air temperature and soil drying, which are conditions unlike in a naturally regenerating stand. From this, it can be assumed that local provenances would not show the best fitness and therefore would not be the best seed source for restoring damaged stands. It was often reported that common beech provenances show local adaptation i.e. better adaptedness of local provenances compared to foreign ones (Mátyás et al, 2009, Gömöry et al. 2015, Schueler and Liesebach 2015, Hajek et al. 2016). However, local provenances may also show maladaptation when habitat changes occur (Mátyás et al. 2009). Considering that climate conditions in the area of Medvednica have significantly changed (DHMZ 2013), which is most likely pronounced at cleared forest stands after windstorm devastation, it is a convincing assumption that local provenances might be less adapted to such habitat 
conditions. Nonetheless, we do not suggest excluding FRM from local (closer to a specific site) provenances in artificial restoration but to consider supplementing them with FRM from provenances which performed better adaptedness to altered environments.

It is interesting to note that provenances originating from higher altitudes performed significantly better (cluster 4 Figure 5,6 ), although these provenances originated from quite different habitats (e.g. compare CH65 and HR27 - Table 1). Horváth (2016) pointed to complete absence of a correlation between growth and climatic parameters of common beech provenances from higher altitudes. Whether this means that such provenances are better adapted to a wider range of habitat conditions or exhibit a wider reaction norm remains an open question. We were particularly surprised by a high and stable performance of the TR62 provenance belonging to Oriental beech. This provenance showed the highest adaptedness (Figure 6), but also phenotypic stability at this trial (Figure 4a), although its original habitat is very different due to all climatic parameters (see Table 1 ). This is the only known provenance of Oriental beech in Croatia and its followup at the Medvednica trial deserves attention, especially in the context of climate change and analysis of its assisted migration.

The question arises whether the established pattern of among-provenance variation might be used as a kind of algorithm in selection of quality (i.e. adapted) FRM for artificial restoration of stands at Medvednica? In our opinion it might, if some assumptions were fulfilled, as well with caution when applying it. The first assumption is that tested provenances well represent genetic diversity of European beech in this part of Europe. The second assumption is that the progenies at the trial well represent genetic constitution of their original provenances. A third assumption is that we accurately determined provenance adaptedness indices, by correcting the data (cAls). In addition, the call for caution in applying the results stems from the fact that the study clearly points to significant heterogeneity of habitat conditions at Medvednica mount. Altitude ranges, diverse exposures, and relief features (as well as other variables) result in large variations in environmental factors (Dobrović et al. 2006). Such conditions make it difficult to identify provenances that would perform a general adaptedness. The obtained "algorithm" (among-provenance variation pattern related to climate variables - Figure 5) can be more reliably applied in selecting FRM for artificial stand restoration where habitat conditions are more similar to those of the trial (altitude of about $750 \mathrm{~m}$ a.s.l., northwestern exposure). In such cases, it may be preferable to use FRM from provenances that, when compared to a particular stand, originate from higher altitudes or slightly lower (up to a minimum of $600 \mathrm{~m}$ a.s.I.), which are relatively warmer (average July temperatures $>18.4^{\circ} \mathrm{C}$ ) and drier during summer season ( $\mathrm{SHM}=30.0$ to 48 ). The reliability of the study results, as well as reliability of consequent recommendations, surely decreases with increased difference between environmental conditions in restoration needed stands and habitat conditions prevailing at the trial during the analyzed test period.

\section{CONCLUSIONS}

The established among-provenance variation pattern can be used as a tool in selecting FRM for artificial restoration of devastated stands at Medvednica mount, at least for habitats featured with environmental conditions similar to the trial site (cleared sites facing northwest at altitudes between 700 and $800 \mathrm{~m}$ a.s.l.). For artificial restoration of such stands it is advisable to use FRM originating from higher altitude provenances, regarding the study results and with the foregoing assumptions. FRM originating from slightly lower altitudes (up to $150 \mathrm{~m}$ lower than a specific site) and relatively warmer and drier habitats (mean July temperatures $>18.4^{\circ} \mathrm{C}$; SHM from 30 to 48 ) may be recommended, as well. The heterogeneity of habitat conditions at Medvednica mount necessitates establishment of more provenance trials according to design options more suited to such conditions (e.g. smaller blocks, non-contiguous plots, etc.). Data processing should be carried out to minimize effect of micro-site variations (by addressing spatial autocorrelation with available tools), i.e. to accurately rank provenance performances at a trial site. Generally, this study showed that provenance trials may be utilized as a valuable decision tool in selecting adapted FRM for restoring disturbed forest stands but may also be misleading if not well designed and analyzed.

\section{Author Contributions}

$\mathrm{MI}$ and SB2 conceived and designed the research; SB1, ML and NĆ carried out the field measurements; SB1 and SB2 processed the data and performed statistical analysis; $\mathrm{MI}$ secured the research funding; MI and SB2 supervised the research; SB1 and SB2 wrote the manuscript. ML, NĆ and MI helped to draft the manuscript.

\section{Funding}

This research has been fully supported by the Croatian Science Foundation under the project IP-2013-11-8131 "Conservation of genetic resources of forest trees in light of climate changes (ConForClim)".

\section{Acknowledgments}

Experimental plants were grown and provided by the ThünenInstitute of Forest Genetics in Grosshansdorf, Germany. The field trial was set up and has been maintained with help of the Croatian Forests Ltd. (Forest Range Administration Zagreb, Forest Office Zagreb). The field trial is a part of the 2007 international series of beech provenance trials initiated by Dr. Georg von Wühlisch. 


\section{REFERENCES}

Anić I, 2007. Forest management systems in lowland forests of Croatia. In: Hobza P (ed) Forest Management Systems and Regeneration of Floodplain Forest Sites, Brno, Czech Republic, 8-9 October 2010. Mendel University of Agriculture and Forestry Brno and The Czech Forest Society, Brno, Czech Republic, pp. 3140.

Balija P, 2015. Rupe na ogoljeloj Medvednici vide se i iz grada, pogledajte koliko je toga uništeno. Available online: https:// www.vecernji.hr/zagreb/rupe-na-ogoljeloj-medvednici-vide-sei-iz-grada-pogledajte-koliko-je-unisteno-1009157 (24 February 2020).

Chmura DJ, Rozkowski R, 2002. Variability of beech provenances in spring and autumn phenology. Silvae Genet 51(2): 123-127.

Cotterill P, James J, 1984. Number of offspring and plot sizes required for progeny testing. Silvae Genet 23: 203-208.

Demšar J, Curk T, Erjavec A, Gorup Č, Hočevar T, Milutinovič $M$, Možina $M$, Polajnar $M$, Toplak $M$, Starič A, 2013. Orange: data mining toolbox in Python. J Mach Learn Res 14(35): 2349-2353.

DHMZ, 2013. Sixth National Communication of the Republic of Croatia under the United Nation Framework Convention on the Climate Change (UNFCCC), Selected sections in chapters: 7. Climate change impacts and adaptation measures, 8. Research, systematic observation and monitoring. Croatian Meteorological and Hydrological Service, Zagreb, Croatia, pp 68-73. Available online: https://klima.hr/razno/publikacije/NIKP6 DHMZ.pdf (10 October 2019).

Dobrović I, Safner T, Jelaska SD, Nikolić T, 2006. Ecological and phytosociological characteristics of the association AbietiFagetum pannonicum (Rauš 1969) on Mt. Medvednica (NW Croatia). Acta Bot Croat 65(1): 41-55.

Dounavi A, Netzer F, Ćelepirović N, Ivanković M, Burger J, Figueroa AG, Schön S, Simon J, Cremer E, Fussi B, Konnert M, Rennenberg $H, 2016$. Genetic and physiological differences of European beech provenances ( $F$. sylvatica L.) exposed to drought stress. Forest Ecol Manag 361: 226-236. https://doi.org/10.1016/i. foreco.2015.11.014.

Dutkowski GW, Silva JCe, Gilmour AR, Lopez GA, 2002. Spatial analysis methods for forest genetic trials. Can J For Res 32(12): 2201-2214. https://doi.org/10.1139/x02-111.

Dutkowski GW, Silva JCe, Gilmour AR, Wellendorf H, Aguiar A, 2006. Spatial analysis enhances modelling of a wide variety of traits in forest genetic trials. Can J For Res 36(7): 1851-1870. https://doi. org/10.1139/x06-059.

Epperson BK, 1992. Spatial structure of genetic variation within populations of forest trees. New Forest 6: 257-278. https://doi. org/10.1007/BF00120648.

Funda T, Lstiburek M, Klápště J, Permedlová I, Kobliha J, 2007. Addressing spatial variability in provenance experiments exemplified in two trials with black spruce. J For Sci 53: 47-56. https://doi.org/10.17221/2135-JFS.

Gömöry D, Paule L, Gömöryová E, 2011. Effects of microsite variation on growth and adaptive traits in a beech provenance trial. $J$ For Sci 57: 192-199. https://doi.org/10.17221/88/2010-JFS.

Gömöry D, Ditmarová L', Hrivnák M, Jamnická G, Kmet' J, Krajmerová D, Kurjak D, 2015. Differentiation in phenological and physiological traits in European beech (Fagus sylvatica L.). Eur J Forest Res 134: 1075-1085. https://doi.org/10.1007/s10342015-0910-2.

Hajek P, Kurjak D, von Wühlisch G, Delzon S, Schuldt B, 2016. Intraspecific Variation in Wood Anatomical, Hydraulic, and Foliar Traits in Ten European Beech Provenances Differing in Growth Yield. Front Plant Sci. https://doi.org/10.3389/fpls.2016.00791.

Hamann A, Namkoong G, Koshy MP, 2002. Improving Precision of Breeding Values by Removing Spatially Autocorrelated Variation in Forestry Field Experiments. Silvae Genet 51: 210-215.
Hamann A, Gylander T, Chen P, 2011. Developing seed zones and transfer guidelines with multivariate regression trees. Tree Genet Genomes 7: 399-408. https://doi.org/10.1007/s11295010-0341-7.

HINA, 2019. Milijuni gubitaka zbog olujnog nevremena na Medvednici. Available online: https://www.nacional.hr/milijunigubitaka-zbog-olujnog-nevremena-na-medvednici/ (24 February 2020).

Horváth A, 2016. Beech adaptation to climate change according to provenance trials in Europe. PhD Thesis, University of West Hungary, Faculty of Forestry, Sopron, Hungary.

Horváth A, Mátyás C, 2016. The decline of vitality caused by increasing drought in a beech provenance trial predicted by juvenile growth. South-East Eur For 7(1): 21-28. https://doi. org/10.15177/seefor.16-06.

Ishizuka W, Goto S, 2012. Modeling intraspecific adaptation of Abies sachalinensis to local altitude and responses to global warming, based on a 36-year reciprocal transplant experiment. Evol Appl 5(3): 229-244. https://doi.org/10.1111/i.17524571.2011.00216.x.

Ivanković M, Popović M, Katičić I, von Wuehlisch G, Bogdan S, 2011. Quantitative Genetic Variation of European Beech (Fagus sylvatica L.) Provenances from the Southeastern Europe. Sum List 135(13): 25-37.

Ivetić V, Devetaković J, 2016. Reforestation challenges in Southeast Europe facing climate change. Reforesta 1: 178-220. https://doi. org/10.21750/10.21750/REFOR.1.10.10.

Kleinschmit JR, Kownatzki D, Gregorius H-R, 2004. Adaptational characteristics of autochthonous populations - consequences for provenance delineation. Forest Ecol Manag 197(1-3): 213-224. https://doi.org/10.1016/i.foreco.2004.05.037.

Kremer A, Ronce O, Robledo-Arnuncio JJ, Guillaume F, Bohrer G, Nathan R, Bridle JR, Gomulkiewicz R, Klein EK, Ritland K, 2012. Long-distance gene flow and adaptation of forest trees to rapid climate change. Ecol Lett 15(4): 378-392. https://doi. org/10.1111/j.1461-0248.2012.01746.x.

Libby WJ, Cockerham CC, 1980. Random non-contiguous plots in interlocking field layouts. Silvae Genet 29: 183-190.

Magnussen S, 1993. Bias in genetic variance estimates due to spatial autocorrelation. Theor App/ Genet 86: 349-355.

Matić S, 1999. The forests of Croatia - country report. In: Diaci J (ed) Virgin Forests and Forest Reserves in Central and East European Countries. Biotechnical Faculty, Department of Forestry and Renewable Forest Resources, Ljubljana, Slovenia, pp. 17-23.

Mátyás C, 1996. Climatic adaptation of trees: rediscovering provenance tests. Euphytica 92: 45-54. https://doi.org/10.1007/ BF00022827.

Mátyás C, Božič G, Gömöry D, Ivanković M, Rasztovits E, 2009. Juvenile growth response of European beech (Fagus sylvatica L.) to sudden change of climatic environment in SE European trials. IForest 2(6): 213-220. https://doi.org/10.3832/ifor0519-002.

Müller M, Finkeldey R, 2016. Genetic and adaptive trait variation in seedlings of European beech provenances from Northern Germany. Silvae Genet 65(2): 65-73. https://doi.org/10.1515/ sg-2016-0018.

Neumann M, Mues V, Moreno A, Hasenauer H, Seidl R, 2017. Climate variability drives recent tree mortality in Europe. Glob Change Biol 23(11): 4788-4797. https://doi.org/10.1111/ gcb.13724.

Pluess AR, Frank A, Heiri C, Lalagüe $H$, Vendramin GG, OddouMuratorio S, 2016. Genome-environment association study suggests local adaptation to climate at the regional scale in Fagus sylvatica. New Phytol 210(2): 589-601. https://doi.org/10.1111/ nph.13809. 
Rehfeldt GE, Ying CC, Spittlehouse DL, Hamilton DA, 1999. Genetic Responses to Climate in Pinus Contorta: Niche Breadth, Climate Change, and Reforestation. Ecol Monogr 69(3): 375-407. https:// doi.org/10.1890/0012-9615(1999)069[0375:GRTCIP]2.0.CO;2.

Robson TM, Sánchez-Gómez D, Cano FJ, Aranda I, 2012. Variation in functional leaf traits among beech provenances during a Spanish summer reflects the differences in their origin. Tree Genet Genomes 8: 1111-1121. https://doi.org/10.1007/s11295-0120496-5.

Savolainen O, Pyhäjärvi T, 2007. Genomic diversity in forest trees. Curr Opin Plant Biol 10(2): 162-167. https://doi.org/10.1016/j. pbi.2007.01.011.

Schueler S, Liesebach M, 2015. Latitudinal population transfer reduces temperature sum requirements for bud burst of European beech. Plant Ecol 216: 111-122. https://doi. org/10.1007/s11258-014-0420-1.

Von Wuehlisch G, Krusche D, Muhs HJ, 1995. Variation in Temperature Sum Requirement for Flushing of Beech Provenances. Silvae Genet 44: 343-346.
Von Wuehlisch G, Ballian D, Bogdan S, Forstreuter M, Giannini R, Götz B, Ivanković M, Orlović S, Pilipović A, Šijačić-Nikolić $M$, 2010. Early results from provenance trials with European beech established 2007. In: COST E52" Evaluation of Beech Genetic Resources for Sustainable Forestry" Final Meeting. Book of Abstracts, pp. 4-6.

Vuletić D, Kauzlarić Ž, Balenović I, Krajter Ostoić S, 2014. Assessment of Forest Damage in Croatia Caused by Natural Hazards in 2014. South-East Eur For 5(1): 65-79. https://doi.org/10.15177/ seefor.14-07.

Wang T, Hamann A, Spittlehouse DL, Mrdock TQ, 2011. ClimateWNA-High - Resolution Spatial Climate Data for Western North America. J Appl Meteorol Climatol 51: 16-29. https://doi. org/10.1175/JAMC-D-11-043.1.

Westfall RD, 1992. Developing Seed Transfer Zones. In: Fins L, Friedman ST, Brotschol JV (eds), Handbook of Quantitative Forest Genetics. Springer, Dordrecht, The Netherlands, pp. 313-350. https://doi.org/10.1007/978-94-015-7987-2 9.

Zas R, 2006. Iterative kriging for removing spatial autocorrelation in analysis of forest genetic trials. Tree Genet Genomes 2: 177-185. https://doi.org/10.1007/s11295-006-0042-4. 